\title{
Understanding rarity: A review of recent conceptual advances and implications for conservation of rare species
}

\author{
by C. Ronnie Drever ${ }^{1}$, Mark C. Drever² and Darren J.H. Sleep ${ }^{3}$
}

\begin{abstract}
Rare species carry a connotation of uniqueness, of being especially valuable, and of heightened extinction risk. We review the literature regarding rare species and link rarity and risk concepts to jurisdictional rarity and how to allocate conservation efforts to rare species gone long undetected. Conservation actions for rare species should be prioritized based on best available information of population trends and thresholds of minimum viable population or geographic range size. For species rare in some geopolitical jurisdictions but common elsewhere, we recommend prioritizing conservation action by assessing beyond jurisdictional boundaries to assess stewardship responsibility relative to the global distribution and at-risk status of the species in question. For making the thorny decision about when to stop managing or monitoring a long-undetected rare species, it may be optimal to continue conservation efforts for a long time, especially if the species has considerable social, economic or ecological value. Recent advances based on theories of optimality provide a replicable and transparent process upon which these decisions can be based.
\end{abstract}

Key words: rare species, conservation, extinction risk, jurisdictional rarity, stewardship responsibility, potentially extinct species

\section{RÉSUMÉ}

Le caractère unique, la valeur spéciale et le risque accru d'extinction sont des caractéristiques associées aux espèces rares. Nous avons effectué une revue de la littérature portant sur les espèces rares et lié les concepts de rareté et de risque à leur définition légale ainsi quétudié la façon d’allouer des efforts de conservation à des espèces rares restées longtemps non détectées. Les mesures de protection des espèces rares doivent être classées prioritairement en fonction de la meilleure information disponible sur les tendances populationnels et le nombre minimal d'individus formant une population viable ou l'aire minimale de distribution géographique. Dans le cas d’espèces rares dans certaines juridictions géopolitiques mais communes ailleurs, nous recommandons de prioriser les mesures de protection en évaluant, au-delà des frontières juridictionnelles, la responsabilité de gestion par rapport à lensemble de la distribution et au statut de précarité des espèces considérées. Le choix difficile du moment où arrêter la gestion, ou le suivi, d'une espèce rare restée longtemps non détectée, pourrait se baser sur le fait qu'il peut être optimal de maintenir les mesures de protection pour une longue période, surtout si l'espèce a une grande valeur sociale, économique ou écologique. Des observations récentes basées sur les théories de loptimalité permettent d'établir un processus transparent et pouvant être reproduit sur lequel baser ces choix.

Mots clés : espèces rares, protection, risque d'extinction, rareté juridictionnelle, responsabilité de gestion, espèce en danger de disparition

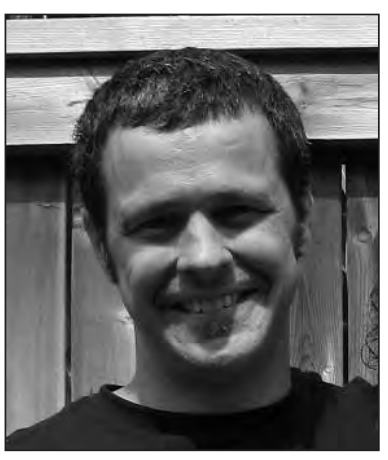

C. Ronnie Drever

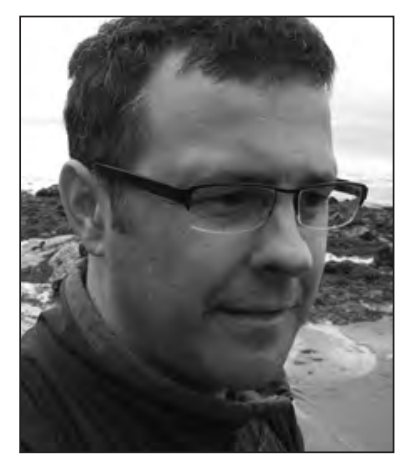

Mark C. Drever

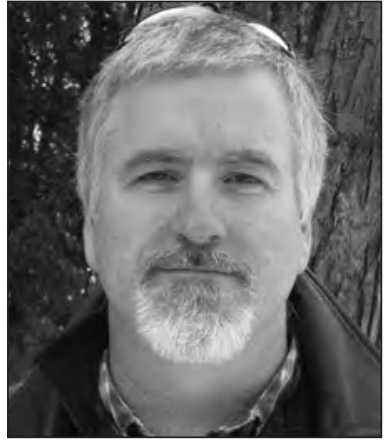

Darren J.H. Sleep

\footnotetext{
${ }^{1}$ Forest Ecologist, The Nature Conservancy - Canada Program, 506-250 City Centre Ave., Ottawa, Ontario K1R 6K7. E-mail: cdrever@tnc.org. Corresponding author.

${ }^{2}$ Centre for Applied Conservation Research, University of British Columbia, 2424 Main Mall, Vancouver, British Columbia V6T 1 Z4. E-mail: mdrever@interchange.ubc.ca

${ }^{3}$ National Council for Air and Stream Improvement Inc., P.O. Box 1036, Station B, Montreal, Quebec H3B 3K5. E-mail: dsleep@ncasi.org
} 


\section{Introduction}

The concept of rarity, i.e., the presence and persistence of rare species, carries a connotation of scarcity, uniqueness or being especially valuable. Rarity is associated with a heightened probability of extinction, and rare species are placed on conservation lists (e.g., the Red List of the International Union for Conservation of Nature) or protected using a variety of legislative tools (e.g., protected areas, endangered species legislation). Conservation case histories underline the link between rarity and population viability; for instance, Bachman's Warbler (Vermivora bachmanii Audubon) was a rare species driven to functional extinction following habitat loss by intensive forest clearing and draining of its wintering grounds and swamp-forest breeding grounds (BirdLife International 2009). Nevertheless, several examples exist of rare species rebounding from small abundances, such as the increases in populations of Peregrine Falcons and Bald Eagles following the banning of organochlorides in North America (Titus and Fuller 1990, Kirk and Hyslop 1998).

Ecologists recognized long ago the asymmetry of how abundances are distributed across a community of species; typically, many species have relatively low abundances and a reduced number have high abundances, i.e., most species are rare and only a few are very common (Fisher et al. 1943, Preston 1948, MacArthur 1957). While this seemingly paradoxical pattern among species has been observed for a long time (Preston 1948), only recently have advances in community ecology, namely niche and neutral theory, shed light on the reasons underlying the pattern (Magurran and Henderson 2003, Chisolm and Pacala 2010, Rosindell et al. 2011). A principal implication of this pattern is all rare species are not necessarily at-risk, although many are, and nor are all equally prone to extinction. Rather, rare species may best be understood as species whose low abundances or restricted ranges make them vulnerable to population declines or range contractions, and thus deserve special attention for the conservation of biodiversity.

In this review, we discuss rarity in the context of recent ecological theory and conservation policy. We focus initially on clarifying what is meant by "rarity" in conservation science, what constitutes a rare species, how rarity is determined, and how rarity relates to extinction risk and threat status. We then link these ideas to two key issues in the conservation of rare species: how to deal with species rare in one jurisdiction but common in neighbouring jurisdictions, and how to allocate conservation efforts to rare species gone undetected for a long time.

\section{What is Rarity?}

Rarity is defined in a wide variety of ways, but all definitions of rare species include the attributes of low abundance (hereafter used synonymously with "population size") or small geographic range size (Gaston 1994). Other definitions include narrow habitat specificity (Waldron et al. 2006), specialized life history (Davies et al. 2004), taxonomic distinctness (Freitag and Van Jaarsveld 2011), transitory existence (Magurran and Henderson 2003), and low dispersal capacity (Hedderson 1992, Murray et al. 2002), either as stand-alone attributes or as additional to low abundance and/or small geographic range size. However, Gaston (1994) argued that such additional attributes can confound the state of rarity with the causes that lead to it, and favoured the simpler definition of low abundance and/or small geographic range size. These two attributes lend themselves more easily to quantitative analyses than other attributes and can provide absolute assessments of rarity, rather than relative assessments based on comparisons with other species in a given community (see below: Speciesabundance distributions and relative measures of rarity). Moreover, focusing on these two attributes allows a key distinction among rare species that need to be protected in different ways, that is, among species that have small populations at a single locality versus species that have small populations but widespread distributions (Drury 1974). In this review, we heed Gaston's (1994) advice and define rare species principally in terms of abundance and/or geographic range size. This approach complements recent comprehensive frameworks that assess conservation status of species, such as the Red List of the International Union for Conservation of Nature (IUCN 2001) and NatureServe criteria (Master et al. 2009); these frameworks focus primarily on abundance and distribution and refer to other traits such as habitat specificity when either there are evident threats to the persistence of a species or when significant uncertainties exist with the data on a species' abundance, trend, and distribution (IUCN 2001). Finally, abundance itself is one of the best correlates of extinction risk, relative to many other biological traits (O'Grady et al. 2004), and therefore a focus on species abundance provides a direct link between rarity and extinction risk.

\section{Conservation of Rare Species and Jurisdictional Boundaries}

Being rare is associated with a number of attributes that can complicate conservation action. A lack of data or survey effort results in limited information about the occurrences of any species, but especially for very rare species. The only mitigation to a lack of data is increased search effort, but depending on the nature of the species in question, sufficient searching is not always economically feasible. This situation can lead to challenges in designating conservation areas or landscape management schemes for rare species. Set-aside areas may be insufficient to maintain the species in question, habitat conserved may not reflect the true ecological needs of the species, or alternatively, conservation measures may be inefficient, overly broad or unwarranted. Further, conservation areas based on historic distributions may not be appropriate, as habitat may have changed dramatically and restoration may not be technically feasible. Therefore, the high costs of search effort for very rare species mean that trade-offs can exist between continued monitoring and conservation action, and these trade-offs should be analyzed in an optimization framework to ensure efficient use of resources (Possingham et al. 2001).

Jurisdictional boundaries can affect rarity designations when the entire range of a species is not considered in conservation decisions because a significant portion of the range is located in a neighbouring jurisdiction. Local abundances of a species typically vary widely over its geographic range, and often do so in a systematic way (Brown et al. 1995; but see Sagarin and Gaines 2002). Every species can therefore be relatively rare somewhere in its range. When geopolitical boundaries transect a species' range at its peripheries, a species can be 
rare in one jurisdiction and common in another, a phenomenon termed "jurisdictional rarity" (Bunnell et al. 2009). Peripheral species can comprise large fractions of threatened species lists: Craig (2006) noted that $70 \%$ of bird species on State-level lists of endangered species from northeastern and Midwestern USA had either no significant population trend or population increases at the continental scale. Similarly, Wells et al. (2010) found that, on average, 51\% (range: $15 \%$ to $100 \%$ ) of bird species on State-level lists in the US were at low risk of extinction at the global level and had a small proportion of their global population within the State. Bunnell et al. (2004) estimated that $70 \%$ (range: $43.2 \%$ to $100 \%$ ) of all listed species in British Columbia can be considered peripheral. Gibson et al. (2009) estimated over 75\% (224) of Canada's approximately 280 terrestrial species at risk are at their northern range periphery in Canada. The conservation of these peripheral species can be controversial because listing and allocation of scarce conservation resources to such species may be at the expense of conservation action for species for which conservation resources could make a more important contribution to persistence (Hunter and Hutchinson 1994, Possingham et al. 2002). This allocation of resources can be especially problematic in cases where there may be no net species loss in a jurisdiction because range contraction of one peripheral species is associated with the range expansion of a different peripheral species occupying a similar niche (e.g., Western Screech-Owl (Megascops kennicottii Elliot) and Barred Owl (Strix varia Barton) (Elliot 2006).

The issues posed by peripheral species in conservation planning for protected areas are well-documented (Erasmus et al. 1999, Wells et al. 2010). For example, Rodrigues and Gaston (2002) demonstrated how consideration of geopolitical boundaries necessitates multiple representations of the same species across the landscape, such that the area needed to adequately represent bird species in southern Africa was ten times larger when political boundaries were considered. That said, many jurisdictions make protection provisions for populations of peripheral species on the basis of ecological representation within the boundaries of their jurisdictional influence. While multiple conservation efforts in neighbouring jurisdictions may not be optimally efficient, these efforts may nevertheless be collectively effective and help minimize the risk of overall extinction. Therefore, the best approach is likely one that makes efficient use of resources but allows for the increased protection provided by some redundancy in species representation across jurisdictions.

\section{How Does Rarity Relate to Abundance and Range Size?}

The abundance of a species can be enumerated in three basic ways: the total numbers of individuals in a population (absolute population size), the number of individuals in a given area (absolute density), and the number of individuals relative to another population (e.g., rank on a list of species' abundances). The availability of such data varies widely among species but all three measures are potentially useful in the study of rarity. In addition, a distinction must be made between local population estimates that apply only to a given locality, and global population estimates that apply to the entire range of a species. Global population size is likely the most appropriate for defining a species as rare, although no definite threshold of abundance exists to determine that a species is absolutely rare (Gaston 1994). Population thresholds used to define risk of extinction do exist (e.g., a global abundance $<250$ mature individuals is considered globally endangered; IUCN 2001), but the population in question is not necessarily rare at all scales, and its relative rarity (e.g., as compared to a highly imperilled species) may be minor.

The measurement of a species' geographic range size deals with similar inherent complexities to measuring total abundance, and key procedural distinctions must be explicitly made, such as whether to include both breeding and nonreproductive areas. Conservation biologists have standardized two measures of geographic range size (Gaston 1994). The first is the Extent of Occurrence (EOO), the area encompassing the entire spatial limits of where a species has been found. The EOO is often characterized as the latitudinal and/or longitudinal limits of the geographic range size or the minimum convex polygon (MCP) in a geographic information system, i.e., the smallest polygon in which no internal angle exceeds $180^{\circ}$ and that contains all sites (see Gaston and Fuller [2009] for methodological considerations). The second measure is the Area of Occupancy (AOO), which represents a refinement of the EOO, where areas known to be uninhabited or unsuitable have been removed, and thus considered a more accurate measure (Gaston and Fuller 2009). However, the difference between the two measures largely depends on the methods used in determining suitable habitat or species presence, and the two measures will be very similar in instances where AOO is measured crudely. In general, the AOO should be used as a measure of geographic range size for defining rare species because of its greater accuracy (Gaston 1994). Since measures of geographic range size can vary strongly with the spatial scale at which they are measured (Gaston 1991, 1994; Hartley and Kunin 2003), the size of a species' geographic range should be measured at spatial scales that reflect movement patterns of the species in question.

\section{Species-Abundance Distributions and Relative Meas- ures of Rarity}

Rarity is perhaps more often understood as a relative concept that involves comparing a species' abundance to the abundances of other species in the community, most often using species-abundance distributions (SADs; McGill et al. 2007). A SAD is a vector of abundances of all species present in a community, which when plotted as a histogram, typically depicts a "hollow curve", indicating a few species with high abundances and many species with low abundances (Fig. 1a). This hollow curve matches closely other related distributions, such as the distribution of range sizes (Schoener 1987, Gaston 1996) or the distribution of local population densities of a species across its range (Brown et al. 1995). When abundances are log-transformed (typically $\log _{2}$-transformed), the distribution is often normal (Fig. 1b). In addition, SADs can be depicted as a rank-abundance diagram (RAD), where logabundance is plotted against rank (Fig. 1c). RADs are useful visual representations of species richness and species evenness (Whittaker 1965). Species richness is the number of different species in a RAD, and evenness, or comparative abundance, is shown by the slope of the line: in a RAD, a steep slope indicates low evenness with high-ranking species having much higher abundances than low-ranking species 


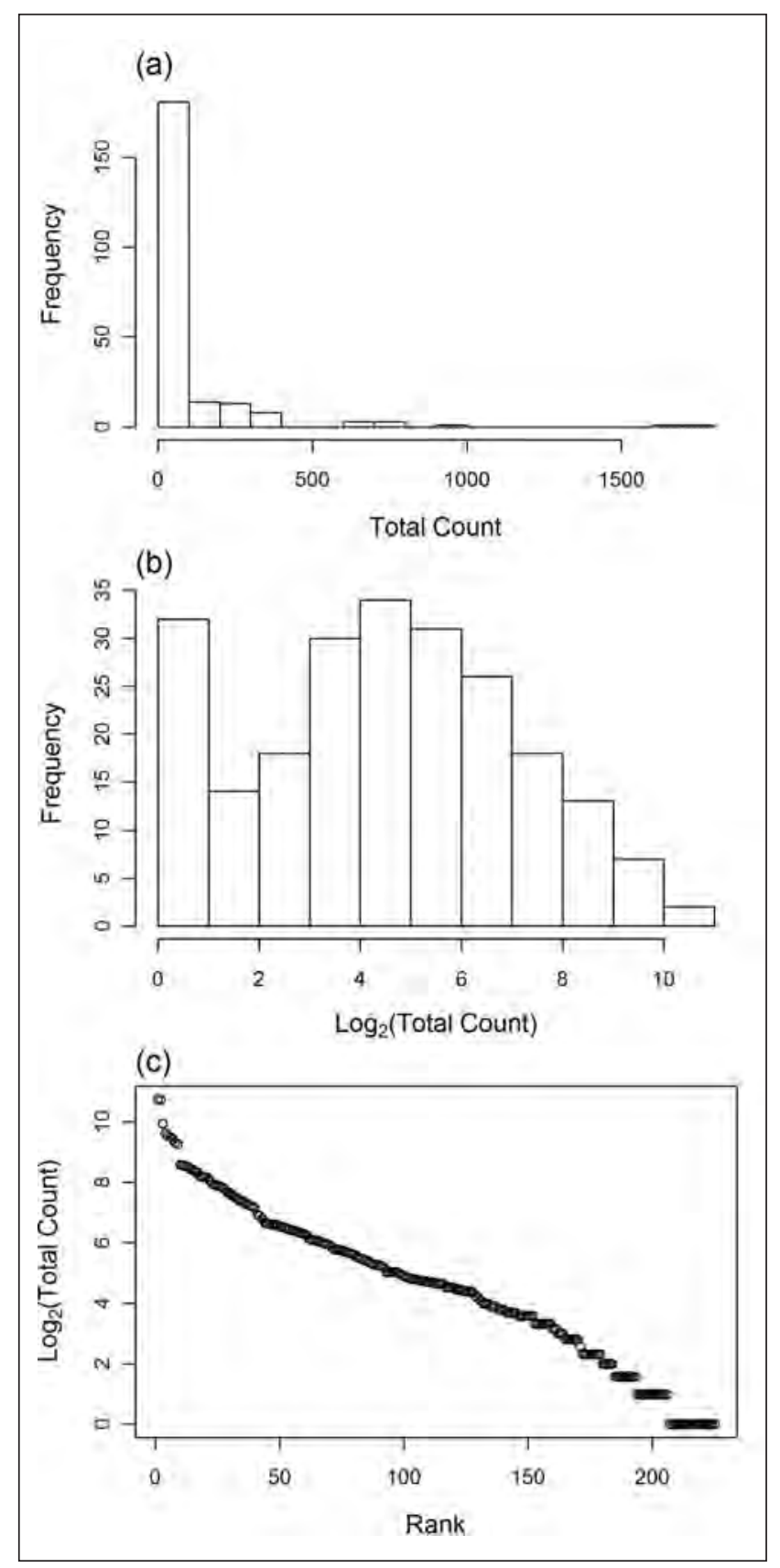

Fig. 1. An example of species abundance distributions: total counts of 225 tree species in 50, 1-ha plots in the Barro Colorado Island, Panama (Condit et al. 2002). Data are presented in three ways: (a) Histogram of total counts of each species binned into different abundance classes on the arithmetic scale. (b) Histogram of total counts of each species binned into different abundance classes on the log2-scale. (c) Rank abundance plot, where log2-abundance is plotted against rank (where highest abundance $=1$, and lowest abundance $=$ number of species in the sample).

whereas a shallow slope indicates high evenness (i.e., abundances of constituent species are similar). None of these three depictions contains information about the identity of species within the community, and therefore depict information on community assemblages in units comparable across different communities (Magurran 1988).
Conservation biologists often use SADs to designate rare species within a community, using an arbitrary proportion of the assemblage with the lowest abundances or geographic range sizes (Magurran 2004). Gaston (1994) recommended using the first quartile of the frequency distribution as a useful cut-off point (the "quartile definition" of rarity), such that in an assemblage of 100 species, the 25 species with the lowest abundances or smallest geographic range sizes would be considered rare (e.g., Drever et al. 2010). This quartile is large enough to capture most rare species, even in the usual circumstances when poor sampling results in many species having low abundances, and is consistent with a large number of studies that have used similar relative definitions of rarity (Gaston 1994). The main disadvantage of this definition is that a particular species may move in and out of the rare category over time, even if its abundance and geographic range size do not change, but when the abundances and ranges of other species in the assemblage change; thus, care should be taken when using rarity derived this way to infer relative conservation priority. Moreover, the rarity assessment is relative to the study area, does not deal with undetected species, and hinges fundamentally on the size and location of the area of analysis. As a caveat, this approach should ensure the SAD be constructed at a spatial scale greater than the planning unit (Gaston 1994).

The quartile definition (or another proportion) has been used to compile lists of rare species for conservation planning, for instance to select species for focal attention (Hannon et al. 2004) or for evaluating alternative design schemes for protected areas (Williams et al. 1996). Hannon et al. (2004) used relative abundances to identify rare bird species potentially atrisk from forestry activities in the boreal mixedwood ecoregion in Alberta. Similarly, several studies used the quartile definition to compile rare species lists and showed that protected areas delineated to maximize the conservation of rare species also resulted in the protection of biodiversity more generally. Examples include: birds in Britain (Williams et al. 1996) and in cloud forests of Ecuador (Poulsen and Krabbe 1997), land snails in Hungary (Sólymos and Fehér 2005), and cross-taxon protection of global distributions of bird, mammal, and amphibian species (Grenyer et al. 2006).

Separate SADs for common and rare species may occur, if the occurrence of these two types of species is governed by different processes, e.g., recruitment from outside the studied area or sampling effects for rare species, and local birth/death rates for common species (Gray et al. 2005). This interpretation is consistent with recent macroecological studies that indicate common species are most responsible for large-scale spatial patterns of richness for a variety of taxa, including southern African and British birds (Lennon et al. 2004), Mexican mammals (Vásquez and Gaston 2004), and Greek plants (Mazaris et al. 2008). This nestedness of species richness indicates that conservation of rare species may come as a collateral benefit of conservation aimed at keeping common species common (Rich et al. 2004). For example, ensuring landscape connectivity may facilitate dispersal of ephemeral species among habitat patches, while retaining large proportions of the landscape as suitable habitat.

\section{How Does Rarity Relate to Extinction Risk?}

Rarity, in spite of carrying with it an increased potential for extinction, does not necessarily equate to being "at risk" (i.e., 
Table 1. Criteria for World Conservation Union (IUCN) categories of risk for species (threatened categories only: Critically endangered, Endangered, Vulnerable). Species must meet one main criterion or combination of sub-criteria to be included in a particular category (IUCN 2001).

\begin{tabular}{|c|c|c|c|c|c|c|c|c|}
\hline \multirow[b]{2}{*}{ Risk category } & \multirow[b]{2}{*}{$\begin{array}{c}\text { Population } \\
\text { size } \\
\text { (individuals) }\end{array}$} & \multirow{2}{*}{$\begin{array}{c}\text { Rarity } \\
\begin{array}{c}\text { Area of } \\
\text { occupancy } \\
\left(\mathrm{km}^{2}\right)\end{array}\end{array}$} & \multirow[b]{2}{*}{$\begin{array}{c}\text { Extent of } \\
\text { occurrence } \\
\left(\mathbf{k m}^{2}\right)\end{array}$} & \multirow{2}{*}{$\begin{array}{c}\text { Rate of decline } \\
\text { Percent } \\
\text { decline in } \\
10 \text { years }\end{array}$} & \multicolumn{3}{|c|}{ Fragmentation or population structure } & \multirow[b]{2}{*}{$\begin{array}{l}\text { Probability } \\
\text { of extinction }\end{array}$} \\
\hline & & & & & $\begin{array}{c}\text { Number of } \\
\text { locations }\end{array}$ & $\begin{array}{l}\text { Min. number } \\
\text { of individuals/ } \\
\text { subpopulation }\end{array}$ & $\begin{array}{l}\text { Percent of } \\
\text { individuals } \\
\text { in } 1 \text { sub- } \\
\text { population }\end{array}$ & \\
\hline $\begin{array}{l}\text { critically } \\
\text { endangered }\end{array}$ & $>50$ or $>250$ & $>10$ & $>100$ & $\begin{array}{c}\leq 90 \text { or } \leq 80 \\
\quad \text { or } \leq 25\end{array}$ & 1 & $\leq 50$ & $\geq 90 \%$ & $\begin{array}{l}\geq 50 \% \text { in } \\
10 \text { years }\end{array}$ \\
\hline endangered & $\begin{array}{l}>250 \text { or } \\
>2,500\end{array}$ & $>500$ & $>5,000$ & $\begin{array}{l}\leq 70 \text { or } \leq 50 \\
\quad \text { or } \leq 20\end{array}$ & $\leq 5$ & $\leq 250$ & $\geq 95 \%$ & $\begin{array}{l}\geq 20 \text { in } \\
20 \text { years }\end{array}$ \\
\hline vulnerable & $\begin{array}{l}>1000 \text { or } \\
>10,000\end{array}$ & $>2,000$ & $>20,000$ & $\begin{array}{c}\leq 50 \text { or } \leq 30 \\
\quad \text { or } \leq 10\end{array}$ & $\leq 10$ & $\leq 1000$ & 100 & $\begin{array}{l}\geq 10 \% \text { in } \\
100 \text { years }\end{array}$ \\
\hline
\end{tabular}

being threatened with extinction). Various organizations categorize threats to species persistence using a variety of standards, but the most commonly cited international ranking is the Red List of the International Union for Conservation of Nature (IUCN; Vié et al. 2009; Table 1) The IUCN ranking has seven levels of threats, from "extinct" to "least concern", and includes categories for poorly understood species (data deficient) and those species not examined by the IUCN (not evaluated). Other national or regional evaluation schemes are often based on the IUCN protocol (e.g., COSEWIC 2009). While such schemes are useful for designating species for priority management action (e.g., recovery efforts), they are not designed for identifying species that may be naturally rare, but not currently at-risk, and some schemes may confound these two considerations.

Estimating extinction risk (or the likelihood of population persistence) for long-term planning can be technically challenging. Fieberg and Ellner (2000) showed that precise estimates of extinction probability over a time horizon of $t$ years requires between $5 t$ and $10 t$ years of data. However, data sets for many rare or threatened species are likely to be highly limited in terms of data quantity, be of relatively poor quality, or unlikely to exist. Further, the principal statistical tools used to quantify extinction risk, Population Viability Analysis (PVA) models, can be sensitive to their assumptions and parameter estimates, resulting in wide confidence intervals (Ellner et al. 2002). Wide confidence intervals can reduce the usefulness of PVA models for conservation decisions, suggesting that these models are best used in a decision-making context that evaluates the relative merits of different management scenarios, or for rare species for which reliable data are available (Brook et al. 2002).

A useful threshold for identifying rare species may be whether a species' global population is near or at its minimum viable population (MVP) size. An MVP is defined as the smallest possible abundance that can persist within a specified period and in the face of natural disasters, and demographic, environmental, or genetic stochasticity (Franklin 1980, Shaffer 1981). Estimates of MVPs for plants and vertebrate species have been calculated using a variety of methods, including theoretical considerations of the maintenance of genetic diversity and adaptive potential (Lande 1995, Reed
2005), stochastic population models (Reed et al. 2003, Brook et al. 2006), empirical observations about extinctions (Thomas 1990, Harcourt 2002, Reed and Hobbs 2004), and collections of MVP estimates from multiple sources (Traill et al. 2007). While estimates of MVP vary depending on methods and taxa under consideration, there is general agreement that a population of a few thousand (1000 to 10000 ) breeding individuals represents the lower limit above which a population can be expected to persist for long periods of time (Nunney and Campbell 1993; Table 2). Identifying a rare species for conservation actions depending on its current abundance relative to a 1000 to $10000 \mathrm{MVP}$ is a useful means of linking a species rarity to its probability of extinction, and is consistent with the rarity measure of IUCN's "vulnerable" category of threatened species (IUCN 2001; Table 1).

Similar to considerations of population abundance, another useful threshold for identifying rare species may be to consider any species with a geographic range size that approaches the size that can support a viable population, also known as the minimum viable geographic range size, or the minimum area of suitable habitat (Beier 1993). While understanding which factors contribute to determining the minimum range size is a subject of significant debate, critical thresholds for geographic range size and extinction risk have been developed based on several considerations (Mace et al. 2008). For example, Terborgh and Winter (1983) defined $50000 \mathrm{~km}^{2}$ as the threshold for "narrowly endemic birds", but did not provide a rationale. Gurd et al. (2001) estimated the minimum reserve area that can allow the persistence of the full suite of terrestrial mammals in eastern North America, including the rarest and most vulnerable species, is $5037 \mathrm{~km}^{2}$ (95\% confidence interval: $2700 \mathrm{~km}^{2}$ to $13296 \mathrm{~km}^{2}$ ). The IUCN risk categories of "critically endangered", "endangered", and "vulnerable" have thresholds for range area of $<10 \mathrm{~km}^{2}$, $<500 \mathrm{~km}^{2}$, and $<20000 \mathrm{~km}^{2}$, respectively, and are based on empirical testing and expert opinion (IUCN 2001; Table 1). Further, although not always the case (Gaston and Lawton 1990), a general positive relationship exists between geographic range size and local abundance for many taxa, such that species with large geographic ranges also tend to be locally abundant, both at individual sites or averaged across the sites at which they occur (Brown 1984, Lawton 1993). 
Table 2. Estimates of Minimum Viable Populations (MVP) for various taxa.

\begin{tabular}{|c|c|c|c|c|}
\hline $\begin{array}{l}\text { MVP (number } \\
\text { of individuals) }\end{array}$ & Taxa & $\begin{array}{c}\text { MVP determination } \\
\text { approach }\end{array}$ & Period of persistence & Reference \\
\hline$>2000$ & 203 vertebrate species & $\begin{array}{l}\text { Regression of temporal } \\
\text { variation in population } \\
\text { size and mean } \\
\text { population size }\end{array}$ & 250 years & Reed and Hobbs 2004 \\
\hline 1377 & $\begin{array}{c}1198 \text { species } \\
\text { (629 invertebrates, } \\
529 \text { vertebrates, } \\
30 \text { plants) }\end{array}$ & $\begin{array}{l}\text { Long-term population } \\
\text { abundance time-series } \\
\text { data to estimate } 90 \% \\
\text { probability of persistence }\end{array}$ & 100 years & Brook et al. 2006 \\
\hline$>2000$ & 11 plant species & $\begin{array}{c}\text { Linear regression } \\
\text { of population size and } \\
>95 \% \text { "standard fitness" }\end{array}$ & Perpetuity & Reed 2005 \\
\hline 4169 & $\begin{array}{l}212 \text { species of } \\
\text { vertebrates, plants, } \\
\text { insects and marine } \\
\text { invertebrates }\end{array}$ & $\begin{array}{c}\text { Meta-analysis of } \\
141 \text { studies; employed } \\
\text { General Linear Model } \\
\text { to standardize MVP } \\
\text { estimates }\end{array}$ & $\begin{array}{c}\text { Various, } \\
\text { depending on study }\end{array}$ & Traill et al. 2007 \\
\hline 7000 & 102 vertebrate species & $\begin{array}{c}\text { Population Viability } \\
\text { Analysis using } 99 \% \\
\text { probability of persistence }\end{array}$ & 40 generations & Reed et al. 2003 \\
\hline $500-1000$ & $\mathrm{n} / \mathrm{a}$ & $\begin{array}{c}\text { Theoretical analysis based } \\
\text { on mutational rates and } \\
\text { trait heritability }\end{array}$ & Perpetuity & $\begin{array}{c}\text { Franklin and } \\
\text { Frankham } 1998\end{array}$ \\
\hline 5500 & various & $\begin{array}{c}\text { Literature review } \\
\text { of observed extinctions } \\
\text { and population variability }\end{array}$ & Perpetuity & Thomas 1990 \\
\hline$>3000$ & various & $\begin{array}{l}\text { Literature review } \\
\text { of demographic and } \\
\text { genetic studies }\end{array}$ & Perpetuity & $\begin{array}{c}\text { Nunney and } \\
\text { Campbell } 1993\end{array}$ \\
\hline 5000 & $\begin{array}{c}\text { Drosophila melanogaster } \\
\text { Meigen }\end{array}$ & $\begin{array}{c}\text { Literature review } \\
\text { of empirical and theoretical } \\
\text { genetics studies of mutation } \\
\text { and extinction risk }\end{array}$ & Perpetuity & Lande 1995 \\
\hline
\end{tabular}

Explanations for this relationship are varied and have mixed empirical support (Gaston et al. 1997), with most explanations focusing on niche breadth (Brown 1984) or metapopulation dynamics (Hanski 1991, Gyllenberg and Hanski 1992). The mechanisms that drive this relationship are important in determining the average density of individuals, which relates back to the geographic area that can support a MVP and should thus be explored further.

The area required for a MVP may strongly vary with body size (Damuth 1981, Swihart et al. 1988, Silva and Downing 1994), and therefore allometric relationships can inform the process of designating rare species (Arita et al.1990, Dobson and $\mathrm{Yu}$ 1993). However, the observed relationship between geographic range and body size is complex, may not apply generally to all taxa, and may not have strong enough predictive value to warrant inclusion into assessments of rarity or extinction risk (Gaston and Blackburn 1995). The uncertainties behind the relationship between body size, geographic range size, and population viability had led conservation agencies to ignore body size. Nonetheless, body size is useful for predicting many important ecological factors, including carrying capacity, home range size, rates of competition and predation, and patterns of species diversity (Harestad and Bunnell 1979, Brown et al. 2004). Given the ease with which information on body size can be collected for many species, body size can be used to assign a null expectation of what a species' geographic range size should be, particularly in cases when little other information is available (Dobson et al. 1995). For instance, Silva and Downing (1994) found that estimates of MVP densities of terrestrial mammals were strongly negatively correlated with body size, suggesting the relationship between minimum viable geographic range and body size may be stronger than the relationship between the observed geographic range and body size (Gaston and Blackburn 1996). Further, Diniz-Filho et al. (2005) found the difference between the observed geographic range and minimum viable geographic range size was significantly correlated with extinction risk, as defined by the IUCN threat categories. 
In summary, while many rare species are indeed at-risk, being rare does not necessarily mean at-risk; rarity by itself is, in many cases, an insufficient criterion for prioritizing conservation actions, especially if the rarity designation is relative to other species in a taxon or community. To prioritize conservation actions for rare species, we recommend (i) basing the rarity designation and action prioritization on population trends and thresholds of minimum viable population or geographic range size, and (ii) wherever possible, use the rarity designation together with other evidence of population decline, principally population size and trend (O'Grady et al. 2004), and other data pertaining to body size, habitat loss, documented overharvesting, disease, or other factors that influence near-term persistence.

\section{Dealing with Jurisdictional Rarity}

One potential approach to dealing with jurisdictional rarity and species that are rare near geopolitical boundaries is to ignore peripheral species altogether, such that decisions about resource allocation are based entirely on national- or international-level priorities (Craig 2006). A coordinated conservation strategy could be constructed where composite jurisdictions (states, provinces, etc.) focus on meeting local challenges for species that are of concern across the jurisdictions in question. Within-jurisdiction conservation planning could be based on species lists that exclude or place a low priority on very rare or vagrant species or other species that can have a disproportional effect on designing efficient reserve networks (Rodrigues and Gaston 2002). Alternatively, conservation planning could include peripheral species only if their distribution within the local jurisdiction is disjunct from the rest of the species' range (Bunnell et al. 2004). However, this approach discounts the logistical and political difficulties involved in coordinating a multi-jurisdictional conservation strategy, and perhaps more importantly, the fact that representing a rare species in multiple conservation efforts in neighbouring jurisdictions is consistent with the precautionary principle and helps minimize the overall risk of extinction or extirpation.

Nevertheless, some peripheral species may have important traits for which they merit special consideration (Fraser 2000). First, populations at the peripheries of the range are often genetically distinct, and are thus important for maintaining overall genetic diversity within populations (Hunter and Hutchinson 1994, Lesica and Allendorf 1995). These unique adaptations to local conditions at the range margins may become increasingly important as climate warms and species begin to move to more climatically suitable habitat (Gibson et al. 2009). However, from the perspective of allocating scarce resources, it behooves conservation practitioners to prioritize efforts where genetic distinctiveness is suspected or demonstrated, especially where this distinctiveness offers unique or rare adaptations, rather than being characteristic of a peripheral population that is maladapted or in decline naturally (Bridle and Vines 2007). Second, populations at range margins can persist for long periods of time, and thus range peripheries may be valuable for conserving endangered species and biological diversity (Channell and Lomolino 2000). Third, while not an argument for an explicit consideration into a scheme for conservation classification, peripheral species may have economic or sociopolitical value that generates interest in their conservation by local people (e.g., inter- est in White-headed Woodpecker, Picoides albolarvatus Cassin, by bird watching groups; Fraser 2000). If local jurisdictions are willing to maintain representative species within their boundaries, then the redundancies may result in greater overall protection for rare species. Our recommendation is not to exclude peripheral species, but rather to plan for conservation of rare species across jurisdictions in as coordinated a fashion as possible, thereby improving overall efficiency and better allocating resources to species that are rare across all the jurisdictions in question (Rodrigues and Gaston 2002).

The principal way proposed to deal with jurisdictional rarity is incorporating global status into priority setting (Craig 2006, Bunnell et al. 2009, Wells et al. 2010), and conservation agencies have generally adopted one of two approaches to do so. This first approach, used by the Committee on the Status of Endangered Wildlife in Canada (COSEWIC) and based on guidelines developed by the IUCN for regional assessments (Gärdenfors et al. 2001), consists of modifying the listing process to include the potential for a "rescue effect". The rescue effect occurs when gametes or individuals with a high probability of reproducing successfully immigrate into a jurisdiction, such that extirpation or decline of a wildlife species can be mitigated or avoided. If the potential for rescue from neighbouring jurisdictions is deemed to be high, then risk of extirpation may be reduced, and the status may be downgraded by one level (IUCN 2003, COSEWIC 2009).

As a second approach, agencies can address jurisdictional rarity by assessing the relative responsibility of the jurisdiction in question for the persistence of a rare species. For example, Partners in Flight (PIF), a cooperative effort among government agencies, conservation groups, industry, academics, and others interested in bird conservation, have developed a ranking scheme for all North American birds based on information both on risk (e.g., population status, trend) and on "stewardship responsibility" (Rich et al. 2004, Panjabi et al. 2005). Stewardship responsibility can be measured as the proportion of a species' total range or population that occurs within a jurisdiction, and so places the local risk within a global context. Similarly, Bunnell et al. (2009) outlined a comprehensive decision-making framework for the allocation of conservation resources in British Columbia that uses the concept of stewardship responsibility such that, all else being equal, species with a greater stewardship responsibility are given higher priority than species with lower stewardship responsibility. Stewardship responsibility can be relatively straightforward to estimate, and does not require the same data input as the IUCN's guidelines for regional assessments. The IUCN guidelines focus on the rescue effect and require evaluations of breeding status within jurisdictions, likelihood of present and future immigration and its probable consequences (Gärdenfors et al. 2001), and thus have greater information needs than the concept of stewardship responsibility. That said, making a decision about relative conservation priorities based on detailed information about abundance, distribution, and ingress/egress of individuals would prevent a situation wherein an area that is an important population "source" is discounted because it represents only a small fraction of the overall range. It is unclear whether in practice the two approaches would result in similar resource allocations, although comparisons between IUCN and PIF schemes have yielded generally concordant rankings, particularly for species of high conservation priority (Mehlman et al. 2004). 
In summary, species that are rare in some geopolitical jurisdictions but common elsewhere comprise large proportions of many at-risk species lists and may compromise the efficient use of conservation resources. We recommend that, for prioritizing conservation action for rare species that are not presently designated as at-risk, decision-makers look beyond their jurisdictional boundaries to assess their stewardship responsibility relative to the global distribution and at-risk status of the species in question, and find opportunities to collaborate with neighbouring jurisdictions in the management and monitoring of rare species.

\section{Can a Species be Too Rare to Manage?}

If a rare species has little potential for rescue, and has not been detected in spite of significant search efforts, how and when can the decision be made to abandon search efforts and/or management of the species' habitat in favour of managing other conservation values known to be present? Determining when a species has gone extinct is challenging, especially in the absence of long-term monitoring data, which is often the case for rare species. Historic and current sighting records are often employed to help determine if a species has gone extinct (Duffy 2010). However, the usefulness of sighting records alone to determine extinction may be limited, as many methods perform poorly when probability of detection declines gradually over time, and therefore the ability to correctly estimate time of extinction may be related to the rate of extinction (e.g., sudden vs. gradual; Rivadeneira et al. 2009).

In 2004, sightings were reported of Ivory-billed Woodpeckers (Campephilus principalis Linnaeus), a species thought to have been extinct since 1944, from the Big Woods region of eastern Arkansas, USA (Fitzpatrick et al. 2005). In response to these reports, and despite criticisms about their validity (Jackson 2006, Sibley et al. 2006), more than US\$20 million were spent on a massive recovery effort that involved intensive searches, replanting of more than 20000 ha in bottomland hardwoods, and protection of 4800 ha in the Big Woods of Arkansas (TNC 2010). By 2010, no physical evidence had appeared to support the initial reports and the search effort was suspended (Dalton 2010), although similar sightings were reported elsewhere in the bird's historical range (Hill et al. 2006). The controversy surrounding the Ivory-billed Woodpecker epitomizes the unique conservation challenges posed by cryptic rare species that remain undetected for long periods of time (Scott et al. 2008). The declaration of extinction for such species has legal consequences (e.g., no requirement to protect critical habitat), and surrendering resources too soon may doom the species. Conversely, the continued allocation of scarce conservation resources to extinct species is inefficient and may actually be detrimental, if it results in the siphoning away of resources available for the conservation of other species. These competing costs and benefits suggest an optimum amount of effort can be allocated to the conservation of rare and iconic species.

Trade-offs among management options are typical of many conservation problems, and the resolution of these trade-offs using formal decision theory is an emerging discipline that combines ecological theory, economic considerations, and mathematics to find optimal solutions for the conservation of biodiversity (Possingham et al. 2001, Wilson et al. 2006, Bottrill et al. 2008). The key features of this approach are the specification of a clear, quantifiable conservation objective (e.g., number of individuals), a list of management options with corresponding costs and benefits to the objective (e.g., cost and effect of predator control), a conceptual model describing the dynamics of the systems (e.g., predator-prey model), and specification of constraints (e.g., total budget, time line). A solution is found by running the model under a wide range of scenarios. The optimal solution captures the amount of effort allocated to the management option that best meets the objective. Success of this approach, however, strongly depends on attributing the correct monetary value to species, which can be very difficult to do, although some good progress in the valuation of species and ecosystem services has been made (Heal et al. 2004, Rudd 2009). The incorporation of socio-economic considerations remains a controversial problem in the conservation of endangered species in Canada (Mooers et al. 2007, Findlay et al. 2009), and so methods based on decision theory may provide a transparent process for decision-making.

Chadès et al. (2008) used an optimization framework to examine the problem of when to stop managing or surveying for the recovery of a potentially extinct species, and to determine at what point should they switch their resources from saving the species to simply looking exhaustively for it, or even surrender all together. The authors used a sequential algorithm that assesses the probability of the species' extinction each year, given specific estimates for its economic value (based on, for instance, its ecotourism value or sum of conservation donations), the costs and effectiveness of managing and surveying, and a total budget, to find the optimal solution that maximizes a species' probability of persistence, wherein each year managers decide whether to manage, survey, or abandon. Chadès et al. (2008) found that, as a general rule that works in a range of conditions, it is optimal to first manage a species for a given number of years $\left(T_{\mathrm{m}}\right)$, even if species remains undetected, and subsequently to survey for species for a given number of years $\left(T_{\mathrm{s}}\right)$, after which conservation efforts for the species are abandoned. As the value of species increases relative to management and survey costs, the durations of the management and survey periods $\left(T_{\mathrm{m}}, T_{\mathrm{s}}\right)$ also increase. A worked example for the Sumatran Tiger (Panthera tigris sumatrae Pocock) indicated that it is optimal to manage for 12 years after the last detection of the tiger, and then, if no tigers are observed during the 12-year period, it would be optimal to switch all resources to survey for three years, after which it becomes optimal to surrender if no tigers are found. If at least one tiger is detected within that combined period, the system is reset to manage for another 12 years. Chadès et al. (2008) provided simpler approximations to their algorithm, and thus this approach has the potential to be applicable to a variety of species in similar situations.

In a similar effort, Rout et al. (2010) proposed an equation to minimize the net expected costs of deciding if a species was considered extinct. The authors based their algorithm on the annual costs of management and monitoring, the probability of the species' extinction, the benefit of management (as measured by the decrease in extinction probability achieved), and the value of the species in terms of its importance or priority given its conservation. Using the example of the Ivorybilled Woodpecker, which was last confirmed sighted in 1944, Rout et al. (2010) estimated it would have optimally been declared extinct in 1965 at the latest. 
In summary, we recommend that in making the thorny decision about when to stop managing or monitoring a rare species that has gone long undetected, decision-makers should consider that it may be optimal to continue conservation efforts for a long time, especially if the species has considerable value. Recent advances based on theories of optimality may assist in such decisions and provide a transparent process with which these decisions can be based.

\section{Conclusion}

In reviewing the concept of rarity and related issues, we conclude that while explicit links exist between rarity and extinction risk, rare species are not always "at-risk"; many species in a given community can be considered relatively rare. We suggest rare species that deserve important conservation attention (beyond officially designated at-risk species) are those whose global populations are estimated to be 1000 to 10000 breeding individuals, as this has been found to be near the minimum number that can be expected to persist for long periods. Species that are rare in some geopolitical jurisdictions but common elsewhere comprise large proportions of many at-risk species lists, and two policy alternatives that can deal with this issue strongly recommend looking beyond jurisdictional boundaries to inform the designation decision and stewardship responsibility. Deciding to abandon survey or management efforts is difficult, but conservation planners have options, based on theories of optimality, that can assist in making such decisions in a logical, value-based, and transparent process.

\section{Acknowledgements}

We thank J.R. Bennett, A.J. Koch, A. Lucier, L. Trout, K. Vice, T.B. Wigley and two anonymous reviewers for valuable comments on the manuscript. Funding was provided by the Canada Program of The Nature Conservancy and the National Council for Air and Stream Improvement Inc.

\section{References}

Arita, H.T., J.G. Robinson and K.H. Redford. 1990. Rarity in neotropical forest mammals and its ecological correlates. Conservation Biology 4: 181-192.

Beier, P. 1993. Determining Minimum Habitat Areas and Habitat Corridors for Cougars. Conservation Biology 7: 94-108.

BirdLife International. 2009. Vermivora bachmanii. In IUCN 2011. IUCN Red List of Threatened Species. Version 2011.2 [online] Available from www.iucnredlist.org [Accessed 30 November 2011].

Bottrill, M.C. et al. 2008. Is conservation triage just smart decision making? Trends in Ecology and Evolution 23: 649-654.

Bridle, J.R. and T.H. Vines. 2007. Limits to evolution at range margins: when and why does adaptation fail? Trends in Ecology and Evolution 22 (3): 140-147.

Brook, B.W., M.A. Burgman, H.R. Akçakaya, J.J. O'Grady and R. Frankham. 2002. Critiques of PVA ask the wrong questions: throwing the heuristic baby out with the numerical bath water. Conservation Biology 16: 262-263.

Brook, B.W., L.W. Traill and C.J.A. Bradshaw. 2006. Minimum viable population size and global extinction risk are unrelated. Ecology Letters 9: 375-382.

Brown, J.H. 1984. On the relationship between abundance and distribution of species. The American Naturalist 122: 295-299.

Brown, J.H., J.F. Gillooly, A.P. Allen, V.M. Savage and G.B. West. 2004. Toward a metabolic theory of ecology. Ecology 85: 1771-1789. Brown, J.H., D.W. Mehlman and G.C. Stevens. 1995. Spatial variation in abundance. Ecology 76: 2028-2043.
Bunnell F.L., R.W. Campbell and K.A. Squires. 2004. Conservation priorities for peripheral species: the example of British Columbia. Canadian Journal of Forest Research 34: 2240-2247.

Bunnell, F.L., D.F. Fraser and A.P. Harcombe. 2009. Increasing effectiveness of conservation decisions: a system and its application. Natural Areas Journal 29: 79-90.

Chadès, I., E. McDonald-Madden, M.A. McCarthy, B. Wintle, M. Linkie and H.P. Possingham. 2008. When to stop managing or surveying cryptic threatened species. Proceedings of the National Academy of Sciences of the United States of America 105: 13936-13940. Channell, R. and M. V. Lomolino. 2000. Dynamic biogeography and conservation of endangered species. Nature 403: 84-86.

Chisolm, R.A. and S.W. Pacala. 2010. Niche and neutral models predict asymptotically equivalent species abundance distributions in high-diversity ecological communities. Proceedings of the National Academy of Sciences 36: 15821-15825.

Condit, R. et al. 2002. Beta-diversity in tropical forest trees. Science 295: 666-669.

[COSEWIC]Committee on the Status of Endangered Wildlife in Canada. 2009. COSEWIC's Assessment Process and Criteria. Government of Canada, Ottawa, Ontario, Canada [online]. Available from http://www.cosewic.gc.ca/eng/sct0/assessment_process_e.cfm. Craig, R.J. 2006. Endangered species, provincialism, and a continental approach to bird conservation. Avian Conservation and Ecology 1(2): 1 [online]. Available from http://www.ace-eco.org/vol1/ iss $2 / \operatorname{art} 1 /$.

Dalton, R. 2010. Still looking for that woodpecker. Nature 463: 718-719.

Damuth, J. 1981. Population density and body size in mammals. Nature 290: 699-700.

Davies, K.F., C.R. Margules and J.F. Lawrence. 2004. A synergistic effect puts rare, specialized species at greater risk of extinction. Ecology 85: 265-271.

Diniz-Filho, J.A.F., P. Carvalho, L. M. Bini and N. M. Tôrres. 2005. Macroecology, geographic range size-body size relationship and minimum viable population analysis for new world carnivora. Acta Oecologica 27: 25-30.

Dobson, F.S. and J. Yu. 1993. Rarity in neotropical forest mammals revisited. Conservation Biology 7: 586-591.

Dobson, F.S., J. Yu, and A.T. Smith. 1995. The importance of evaluating rarity. Conservation Biology 9: 1648-1651.

Drever, C.R., J. Snider and M.C. Drever. 2010. Rare forest types in northeastern Ontario: a classification and analysis of representation in protected areas. Canadian Journal of Forest Research 40: 423-435. Drury, W.H. 1974. Rare species. Biological Conservation 6: 162-169.

Duffy, K.J. 2010. Identifying sighting clusters of endangered taxa with historical records. Conservation Biology 25: 392-399.

Elliott, K. 2006. Declining numbers of western Screech-Owl in the Lower Mainland of British Columbia. British Columbia Birds 14: 2-11.

Ellner, S.P., J. Fieberg, D. Ludwig and C. Wilcox. 2002. Precision of population viability analysis. Conservation Biology 16: 258-261.

Erasmus, B.F.N., S. Freitag and K.J. Gaston. 1999. Scale and conservation planning in the real world. Proceedings of the Royal Society B 266: 315-319.

Fieberg, J. and S.P. Ellner. 2000. When is it meaningful to estimate an extinction probability? Ecology 81: 115-143.

Findlay C.S., S. Elgie, B. Giles and L. Burr. 2009. Species listing under Canada's Species at Risk Act. Conservation Biology 23: 1609-1617.

Fisher, R.A., A.S. Corbet and C.B. Williams. 1943. The relation between the number of species and the number of individuals in a random sample of an animal population. Journal of Animal Ecology 12: 42-58.

Fitzpatrick, J.W. et al. 2005. Ivory-billed woodpecker (Campephilus principalis) persists in continental North America. Science 308: 1460-1462. 
Franklin, I.R. 1980. Evolutionary change in small populations. In Soulé, M.E. and B.A. Wilcox (eds.). Conservation biology: An evolutionary-ecological perspective. pp. 135-149. Sinauer Associates. Sunderland, MA.

Franklin, I.R. and R. Frankham. 1998. How large must populations be to retain evolutionary potential? Animal Conservation 1: 69-70.

Fraser, D.F. 2000. Species at the edge: the case for listing of "peripheral" species. In L.M. Darling (ed.) Proceedings of a conference on the biology and management of species and habitats at Risk, Kamloops, B.C., 1999, Vol. 1. BC Ministry of Environment, Lands and Parks, Victoria, BC and University College of the Cariboo, Kamloops, BC. 490 p.

Freitag, S. and A.S. Van Jaarsveld. 2011. Conservation priority of alpine habitat: a floristic approach based on potential distribution of vascular plant species. Biodiversity and Conservation 6: 211-232.

Gärdenfors, U., C. Hilton-Taylor, G.M. Mace and J.P. Rodríguez. 2001. The application of IUCN red list criteria at regional levels. Conservation Biology 15: 1206-1212.

Gaston, K.J. 1991. How large is a species' geographic range? Oikos 61: 434-438.

Gaston, K.J. 1994. Rarity. Chapman \& Hall, London, UK. 205 p.

Gaston, K.J. 1996. Species-range-size distributions: patterns, mechanisms and implications. Trends in Ecology and Evolution 11: 197-201.

Gaston, K.J., and T.M. Blackburn. 1995. Rarity and body size: some cautionary remarks Conservation Biology 9: 210-213.

Gaston, K.J., and T.M. Blackburn. 1996. Conservation implications of geographic range size-body size relationships. Conservation Biology 10: 638-646.

Gaston, K.J., T.M. Blackburn and J.H. Lawton. 1997. Interspecific abundance-range size relationships: an appraisal of mechanisms. Journal of Animal Ecology 66: 579-601.

Gaston, K. J., and R. A. Fuller. 2009. The size of species' geographic ranges. Journal of Applied Ecology 46:1-9.

Gaston, K. J. and J. H. Lawton. 1990. Effects of Scale and Habitat on the Relationship between Regional Distribution and Local Abundance. Oikos 58: 329-335.

Gibson, S.Y., R.C. Van der Marel and B.M. Starzomski. 2009. Climate change and conservation of leading-edge peripheral populations. Conservation Biology 23: 1369-1373.

Gray J.S., A. Bjorgesaeter, and K.L. Ugland. 2005. The impact of rare species on natural assemblages. Journal of Animal Ecology 74: 1131-1139.

Grenyer, R. et al. 2006. Global distribution and conservation of rare and threatened vertebrates. Nature 444: 93-96.

Gurd, D.B., T.D. Nudds and D.H. Rivard. 2001. Conservation of Mammals in Eastern North American Wildlife Reserves: How Small Is Too Small? Conservation Biology 15: 1355-1363.

Gyllenberg, M. and I. Hanski. 1992. Single-species metapopulation dynamics: a structured model. Theoretical Population Biology 42: 35-66.

Hannon S.J., S.E. Cotterill and F.K.A. Schmiegelow. 2004. Identifying rare species of songbirds in managed forests: application of an ecoregional template to a boreal mixedwood system. Forest Ecology and Management 191: 157-170.

Hanski, I. 1991. Single-species metapopulation dynamics: concepts, models and observations. Biological Journal of the Linnean Society 42: $17-38$.

Harcourt, A.H. 2002. Empirical estimates of minimum viable population sizes for primates: tens to tens of thousands? Animal Conservation 5: 237-244.

Harestad, A.S. and F.L. Bunnell. 1979. Home Range and Body Weight - A Reevaluation. Ecology 60: 389-402.

Hartley, S. and W.E. Kunin. 2003. Scale dependency of rarity, extinction risk, and conservation priority. Conservation Biology 17: $1559-1570$
Heal, G.M. et al. 2004. Valuing Ecosystem Services: Toward Better Environmental Decision-Making. National Academy Press, Washington, DC. 277 p.

Hedderson, T.A. 1992. Rarity at range limits: dispersal capacity and habitat relationships of extraneous moss species in a boreal Canadian National Park. Biological Conservation. 59: 113-120.

Hill, G.E., D.J. Mennill, B.W. Rolek, T.L. Hicks and K.A. Swiston. 2006. Evidence suggesting that Ivory-billed Woodpeckers (Campephilus principalis) exist in Florida. Avian Conservation and Ecology - Écologie et conservation des oiseaux 1(3): 2 [online]. Available from http://www.ace-eco.org/vol1/iss3/art2/

Hunter, M.J. and A. Hutchinson. 1994. The virtues and shortcomings of parochialism: conserving species that are locally rare, but globally common. Conservation Biology 8: 1163-1165.

[IUCN] International Union for the Conservation of Nature. 2001. IUCN Red List categories and criteria: version 3.1. IUCN, Gland, Switzerland, and Cambridge, UK.

2003. Guidelines for Application of IUCN Red List Criteria at Regional Levels: Version 3.0. IUCN Species Survival Commission.IUCN, Gland, Switzerland and Cambridge, UK.

Jackson, J.A. 2006. Ivory-billed woodpecker (Campephilus principalis): Hope, and the interfaces of science, conservation, and politics. The Auk 123: 1-15.

Kirk, D.A. and C. Hyslop. 1998. Population status and recent trends in Canadian raptors: a review. Biological Conservation 83: 91-118.

Lande, R. 1995. Mutation and conservation. Conservation Biology 9: 782-791.

Lawton, J. H. 1993. Range, population abundance and conservation. Trends in Ecology and Evolution 8: 409-413.

Lennon, J.J., P. Koleff, J.J.D. Greenwood and K.J. Gaston. 2004. Contribution of rarity and commonness to patterns of species richness. Ecology Letters 7(2): 81-87.

Lesica, P. and F.W. Allendorf. 1995. When are peripheral-populations valuable for conservation? Conservation Biology 9: 753-760.

MacArthur, R.H. 1957. On the relative abundance of bird species. Proceedings of the National Academy of Sciences 43: 293-295.

Mace, G.M., N.J. Collar, K.J. Gaston, C. Hilton-Taylor, H.R. Akcakaya, N. Leader-Williams, E.J. Milner-Gulland, and S.N. Stuart. 2008. Quantification of extinction risk: IUCN's system for classifying threatened species. Conservation Biology 22: 1424-1442. Magurran, A.E. 1988. Ecological Diversity and its Measurement. Croom Helm Limited, London, UK. 179 p.

Magurran, A.E. 2004. Measuring biological diversity. Blackwell Publishing, Oxford, UK. 256 p.

Magurran, A.E. and P.A. Henderson. 2003. Explaining the excess of rare species in natural species abundance distributions. Nature 422: 714-716.

Master, L., D. Faber-Langendoen, R. Bittman, G. A. Hammerson, B. Heidel, J. Nichols, L. Ramsay and A. Tomaino. 2009. NatureServe Conservation Status Assessments: Factors for Assessing Extinction Risk. NatureServe, Arlington, VA. 57 p.

Mazaris, A.D., J. Tzanopoulos, A.S. Kallimanis, Y.G. Matsinos, S.P. Sgardelis and J. D. Pantis. 2008. The contribution of common and rare species to plant species richness patterns: the effect of habitat type and size of sampling unit. Biodiversity and Conservation 17: 3567-3577.

McGill, B.J. et al. 2007. Species abundance distributions: moving beyond single prediction theories to integration within an ecological framework. Ecology Letters 10: 995-1015.

Mehlman, D.W., K.V. Rosenberg, J.V. Wells and B. Robertson. 2004. A comparison of North American avian conservation priority ranking systems. Biological Conservation 120: 383-390.

Mooers, A.O., L.R. Prugh, M. Festa-Bianchet and J.A. Hutchings. 2007. Biases in legal listing under Canadian endangered species legislation. Conservation Biology 21: 572-575.

Murray, B.R., P.H. Thrall, A.M. Gill and A.B. Nicotra. 2002. How plant life-history and ecological traits relate to species rarity and commonness at varying spatial scales. Austral Ecology 27: 291-310. 
Nunney, L. and K.A. Campbell. 1993. Assessing minimum viable population size: demography meets population genetics. Trends in Ecology and Evolution 8: 234-239.

O'Grady, J.J. D. H. Reed, B.W. Brook and R. Frankham. 2004. What are the best correlates of predicted extinction risk? Biological Conservation 118: 513-520.

Panjabi, A.O. et al. 2005. The Partners in Flight handbook on species assessment. Version 2005 [online]. Partners in Flight Technical Series No. 3. Rocky Mountain Bird Observatory Web site. Available from http://www.rmbo.org/pubs/downloads/Handbook2005.pdf Possingham, H.P., S.J. Andelman, M.A. Burgman, R.A. Medellín, L.L. Master and D.A. Keith. 2002. Limits to the use of threatened species lists. Trends in Ecology and Evolution 17: 503-507.

Possingham, H. P., S. J. Andelman, B. R. Noon, S. Trombulak and H. R. Pulliam. 2001. Making smart conservation decisions. In M. E. Soulé and G. H. Orians (eds.). Conservation Biology: Research Priorities for the Next Decade. pp. 225-244. Island Press, Washington, DC. Poulsen, B.O. and N. Krabbe. 1997. Avian rarity in ten cloud-forest communities in the Andes of Ecuador: implications for conservation. Biodiversity and Conservation 6: 1365-1375.

Preston, F.W. 1948. The commonness, and rarity, of species. Ecology 29: 254-283.

Reed, D.H. 2005. Relationship between population size and fitness. Conservation Biology 19: 563-568.

Reed, D.H. and G.R. Hobbs. 2004. The relationship between population size and temporal variability in population size. Animal Conservation 7: 1-8.

Reed, D. H., J.J. O’Grady, B.W. Brook, J.D. Ballou and R. Frankham. 2003. Estimates of minimum viable population sizes for vertebrates and factors influencing those estimates. Biological Conservation 113: 23-34.

Rich, T. D. et al. 2004. Partners in Flight North American Landbird Conservation Plan [online]. Cornell Lab of Ornithology, Ithaca, NY. Available from http://www.partnersinflight.org/cont_plan/.

Rivadeneira, M.M., G. Hunt and K. Roy. 2009. The use of sighting records to infer species extinctions: an evaluation of different methods. Ecology 90: 1291-1300.

Rodrigues, A.S.L. and K.J. Gaston. 2002. Rarity and conservation planning across geopolitical units. Conservation Biology 16:674-682.

Rosindell, J., S.P. Hubbell and R.S. Etienne. 2011. The Unified Neutral Theory of Biodiversity and Biogeography at Age Ten. Trends in Ecology and Evolution 26: 340-348.

Rout, T.M., D. Heinze and M.A. McCarthy. 2010. Optimal allocation of conservation resources to species that may be extinct. Conservation Biology 24: 1111-1118.

Rudd, M.A. 2009. National values for regional aquatic species at risk in Canada. Endangered Species Research 6: 239-249.

Sagarin, R.D. and S.D. Gaines 2002. The 'abundant centre' distribution: to what extent is it a biogeographical rule? Ecology Letters 5: 137-147.

Schaffer, M.L. 1981. Minimum population sizes for species conservation. BioScience 31: 131-134.

Schoener, T.W. 1987. The geographical distribution of rarity. Oecologia 74: 161-173.
Scott, J.M., F.L. Ramsey, M. Lammertink, K.V. Rosenberg, R. Rohrbaugh, J.A. Wiens and J.M. Reed. 2008. When is an "extinct" species really extinct? Gauging the search efforts for Hawaiian forest birds and the Ivory-billed Woodpecker. Avian Conservation and Ecology - Écologie et conservation des oiseaux 3(2): 3 [online] Available from http://www.ace-eco.org/vol3/iss2/art3/

Sibley, D.A., L.R. Bevier, M.A. Patten and C.S. Elphick. 2006. Comment on "ivory-billed woodpecker (Campephilus principalis) persists in continental North America". Science 311: 1555.

Silva, M. and J.A. Downing. 1994. Allometric scaling of minimal mammal densities. Conservation Biology 8: 732-743.

Sólymos, P. and Z. Fehér. 2005. Conservation prioritization based on distribution of land snails in Hungary. Conservation Biology 19: 1084-1094.

Swihart, R.K., N.A. Slade and B.J. Bergstrom. 1988. Relating body size to the rate of home range use in mammals. Ecology 69: 393-399. Terborgh, J. and B. Winter. 1983. A method for siting parks and reserves with special reference to Columbia and Ecuador. Biological Conservation 27: 45-58.

[TNC] The Nature Conservancy. 2010. Ivory-billed Woodpecker [online]. Available from http://www.nature.org/ivorybill/

Thomas, C.D. 1990. What do real population dynamics tell us about minimum viable population sizes? Conservation Biology 4: 324-327.

Titus, K. and M. R. Fuller. 1990. Recent trends in counts of migrant hawks from northeastern North America. Journal of Wildlife Management 54: 463-470.

Traill, L.W., J.A. Bradshaw and B.W. Brook. 2007. Minimum viable population size: A meta-analysis of 30 years of published estimates. Biological Conservation 139: 159-166.

Vásquez, L.-B. and K.J. Gaston. 2004. Rarity, commonness, and patterns of species richness: the mammals of Mexico. Global Ecology and Biogeography. 13: 535-542.

Vié, J.-C., C. Hilton-Taylor and S.N. Stuart (eds.) 2009. Wildlife in a Changing World - An Analysis of the 2008 IUCN Red List of Threatened Species. Gland, Switzerland: IUCN. 180 p.

Waldron, J.L., S.H. Bennett, S.M. Welch, M.E. Dorcas, J. D. Lanham and W. Kalinowsky. 2006. Habitat specificity and home-range size as attributes of species vulnerability to extinction: a case study using sympatric rattlesnakes. Animal Conservation 9: 414-420.

Wells, J.V., B. Robertson, K.V. Rosenberg and D.W. Mehlman. 2010. Global versus local conservation focus of U.S. State agency endangered bird species lists. PLoS One 5(1): e8608. doi: 10.1371/journal.pone.0008608.

Whittaker, R.H. 1965. Dominance and diversity in land plant communities: numerical relations of species express the importance of competition in community function and evolution. Science 147: 250-260.

Williams P., D. Gibbons, C. Margules, A. Rebelo, C. Humphries and R. Pressey. 1996. A comparison of richness hotspots, rarity hotspots, and complementary areas for conserving diversity of British birds. Conservation Biology 10: 155-174.

Wilson, K. A., M. McBride, M. Bode and H. P. Possingham. 2006. Prioritising global conservation efforts. Nature 40: 337-340. 